\title{
Diagnostic Reasoning by Hospital Pharmacists: Assessment of Attitudes, Knowledge, and Skills
}

\author{
Kseniya Chernushkin, Peter Loewen, Jane de Lemos, Amneet Aulakh, Joanne Jung, and Karen Dahri
}

\begin{abstract}
Background: Hospital pharmacists participate in activities that may be considered diagnostic. Two reasoning approaches to diagnosis have been described: non-analytic and analytic. Of the 6 analytic traditions, the probabilistic tradition has been shown to improve diagnostic accuracy and reduce unnecessary testing. To the authors' knowledge, pharmacists' attitudes toward having a diagnostic role and their diagnostic knowledge and skills have never been studied.
\end{abstract}

Objectives: To describe pharmacists' attitudes toward the role of diagnosis in pharmacotherapeutic problem-solving and to characterize the extent of pharmacists' knowledge and skills related to diagnostic literacy.

Methods: Pharmacists working within Lower Mainland Pharmacy Services (British Columbia) who spent at least 33\% of their time in direct patient care were invited to participate in a prospective observational survey. The survey sought information about demographic characteristics and attitudes toward diagnosis. Diagnostic knowledge and skills were tested by means of 3 case scenarios. The analysis included simple descriptive statistics and inferential statistics to evaluate relationships between responses and experience and training.

Results: Of 266 pharmacists invited to participate, 94 responded. The attitudes section of the survey was completed by 90 pharmacists; of these, 80 (89\%) agreed with the definition of "diagnosis" proposed in the survey, and 83 (92\%) agreed that it is important for pharmacists to have diagnosis-related skills. Respondents preferred an analytic to a nonanalytic approach to diagnostic decision-making. The probabilistic tradition was not the preferred method in any of the 3 cases. In evaluating 5 clinical scenarios that might require diagnostic skills, on average $84 \%$ of respondents agreed that they should be involved in assessing such problems. Respondents' knowledge of and ability to apply probabilistic diagnostic tools were highest for test sensitivity (average of $61 \%$ of respondents with the correct answers) and lower for test specificity (average of $48 \%$ with correct answers) and likelihood ratios (average of 39\% with correct answers).

Conclusions: Respondents to this survey strongly believed that diagnostic skills were important for solving drug-related problems, but they demonstrated low levels of knowledge and ability to apply concepts of probabilistic diagnostic reasoning. Opportunities to expand pharmacists' knowledge of diagnostic reasoning exist, and the findings reported here

\section{RÉSUMÉ}

Contexte : Les pharmaciens hospitaliers prennent part à des activités pouvant être considérées de nature diagnostique. Deux démarches diagnostiques ont été décrites : non analytique et analytique. Des six traditions analytiques, la tradition probabiliste s’est révélée améliorer la précision du diagnostic et réduire le recours à des tests inutiles. Pour autant que sachent les auteurs, les attitudes des pharmaciens à l'égard d'un rôle diagnostique ainsi que leurs connaissances et aptitudes diagnostiques n'ont jamais été étudiées.

Objectifs : Décrire les attitudes des pharmaciens à l'égard d'un rôle diagnostique dans la résolution des problèmes pharmacothérapeutiques et caractériser l'importance des connaissances ainsi que des aptitudes des pharmaciens en matière de diagnostic.

Méthodes : Des pharmaciens travaillant dans les services de pharmacie de la région du Lower Mainland en Colombie-Britannique et ayant consacré au moins $33 \%$ de leur temps à la prestation de soins directs aux patients ont été invités à participer à un sondage observationnel prospectif. Le sondage visait à obtenir des renseignements sur les caractéristiques démographiques et les attitudes à l'égard du diagnostic. Les connaissances et les compétences en matière de diagnostic ont été évaluées au moyen de trois études de cas. L'analyse comportait des statistiques descriptives simples et des statistiques inférentielles pour évaluer les relations entre les réponses, et l'expérience et la formation.

Résultats : Des 266 pharmaciens invités à participer, 94 ont répondu au sondage. Des 90 pharmaciens qui ont rempli la section sur les attitudes, 80 (89 \%) étaient d'accord avec la définition de " diagnostic " proposée dans le sondage et 83 (92\%) étaient d'accord pour dire qu'il est important pour les pharmaciens de posséder des compétences en matière de diagnostic. Les répondants ont préféré la démarche analytique à la démarche non analytique dans l'établissement du diagnostic. La tradition probabiliste n'était pas la méthode préférée pour aucune des trois études de cas. Dans l'évaluation de cinq contextes cliniques pouvant nécessiter des compétences en matière de diagnostic, en moyenne $84 \%$ des répondants ont affirmé qu'ils devraient prendre part à l'évaluation de tels problèmes. Les connaissances qu'avaient les répondants des outils de diagnostic probabiliste et leurs capacités à les utiliser étaient les plus importantes pour ce qui est de la sensibilité de l'analyse (en moyenne $61 \%$ avaient les bonnes réponses) et moins importantes pour ce qui est de la spécificité de l'analyse (en moyenne $48 \%$ avaient les bonnes réponses) et des rapports de vraisemblance (en moyenne $39 \%$ avaient les bonnes réponses).

Conclusions : Les répondants au sondage croyaient fermement que des compétences diagnostiques étaient importantes pour résoudre les problèmes pharmacothérapeutiques, mais ils possédaient peu de 
indicate that pharmacists would consider such professional development valuable.

Key words: diagnostic literacy, diagnostic traditions, pharmacists' diagnosing, probabilistic diagnostic tools connaissances et d'aptitudes pour appliquer les concepts de la démarche diagnostique probabiliste. Il y place pour bonifier les connaissances des pharmaciens à propos des démarches diagnostiques et les résultats présentés ici indiquent que les pharmaciens considéreraient utile une formation professionnelle en ce sens.

Mots clés : connaissances diagnostiques, traditions diagnostiques, diagnostic établi par les pharmaciens, outils de diagnostic probabiliste

\section{INTRODUCTION}

$\mathrm{R}$ ecent and planned expansion of pharmacists' scope of practice may expose areas where the knowledge and skills of these health care professionals require further development to allow them to fulfill previously underdeveloped roles. ${ }^{1}$ One such area is diagnostic reasoning. Pharmacists have not traditionally self-identified as diagnosticians, but by common definitions of "diagnosis", such skills have been and will increasingly be demanded of them. ${ }^{2}$

Evidence of pharmacists' role in diagnosis comes from the Canadian Blueprint for Pharmacy, which has as 1 of the 6 primary tenets of its vision for pharmacists to "initiate, modify and continue drug therapy ... and order tests". ${ }^{3}$ In the United Kingdom, a long-term effort continues to shift physician functions (including diagnosis and treatment of minor ailments) to pharmacists. $^{4}$ In several jurisdictions, activities such as prescription adaptation, whereby pharmacists independently change or renew prescriptions on the basis of their assessments of patients, require diagnostic reasoning. . $^{5-10}$

In the hospital sector, the 2015 Initiative of the American Society of Health-System Pharmacists (ASHP) includes in the tenets for medication therapy management "performing or obtaining necessary assessments of the patient's health status" and "monitoring and evaluating the patient's response to therapy, including safety and effectiveness" . ${ }^{11}$ The 2015 Initiative of the Canadian Society of Hospital Pharmacists (CSHP) contains nearly identical language related to managing medication therapy. ${ }^{12}$ Several hospitals have given pharmacists the authority to order laboratory tests to facilitate drug therapy decision-making. ${ }^{13,14}$ Although debate about pharmacists' diagnostic role has existed for some time both within the pharmacy profession and between professions (mainly medicine and pharmacy), there is considerable evidence, especially from community practice, that pharmacists commonly engage in diagnosis. ${ }^{15-19}$
There is no generally accepted definition of the term "diagnosis", but the authors' review of a broad spectrum of medical and nonmedical tertiary references ${ }^{20-23}$ led to the following broad definition: "Diagnosis is the outcome of the process of clinical reasoning about the nature of a condition, a process that is based on evaluation of the patient's medical history, signs, and symptoms and review of the results of laboratory tests". By this definition, all of the previously mentioned pharmacist activities appear to demand knowledge and skill in diagnostic reasoning. Some examples are described in Box 1 .

\section{Box 1. Examples of Clinical Scenarios Encountered by Pharmacists That May Require Diagnostic Skills}

Assessing whether a patient with hyponatremia who is receiving selective serotonin reuptake inhibitor therapy has drug-induced SIADH

Determining whether a patient's low mean corpuscular volume anemia is amenable to iron therapy

Deciding on the appropriateness of interventions intended to reduce cardiovascular risk for a patient with no coronary artery disease but a history of "dyslipidemia"

Determining whether the accuracy of a new clinical prediction rule for assessing a patient's bleeding risk while receiving warfarin is sufficient to justify incorporating it into regular practice

Interpreting negative results of microbiologic culture (or $<100 \times 10^{6}$ colony-forming units $/ \mathrm{mL}$ ) in a patient with symptoms suggestive of a urinary tract infection

Evaluating causality by drug therapy in a patient with a severe rash

Deciding on the diagnostic role of performing serum potassium assay in a patient who is receiving furosemide therapy Evaluating signs and symptoms (fever, diarrhea, white blood cell count), as well as interpreting the results of a Clostridium difficile toxin test, in a patient with suspected infection who is not receiving antibiotic therapy

$\mathrm{SIADH}=$ syndrome of inappropriate antidiuretic hormone hypersecretion 
Table 1. Demographic Characteristics of Respondents to a Survey about Pharmacists' Attitudes, Knowledge, and Skills Related to Diagnosis

\begin{tabular}{|c|c|}
\hline Characteristic & $\begin{array}{c}\text { No. }(\%) \text { of } \\
\text { Respondents } \\
(n=93)\end{array}$ \\
\hline \multicolumn{2}{|l|}{$\overline{\text { Practice site* }}$} \\
\hline Vancouver General Hospital & $22(24)$ \\
\hline St Paul's Hospital & $12(13)$ \\
\hline Royal Columbian Hospital & $11(12)$ \\
\hline Surrey Memorial Hospital & $10(11)$ \\
\hline Community sites & $6 \quad(6)$ \\
\hline Lions Gate Hospital & $5 \quad(5)$ \\
\hline Peace Arch Hospital & $5 \quad(5)$ \\
\hline Mount Saint Joseph Hospital & $4(4)$ \\
\hline \multicolumn{2}{|l|}{ Children's and Women's Hospital of } \\
\hline British Columbia & $4 \quad(4)$ \\
\hline Abbotsford Regional Hospital & $4 \quad(4)$ \\
\hline Burnaby General Hospital & $3(3)$ \\
\hline Vancouver Coastal Residential & $3(3)$ \\
\hline Langley Memorial Hospital & $3(3)$ \\
\hline Richmond Hospital & $3(3)$ \\
\hline Chilliwack General Hospital & $2(2)$ \\
\hline Eagle Ridge Hospital & $2(2)$ \\
\hline GF Strong & $1(1)$ \\
\hline UBC Hospital & $1(1)$ \\
\hline Squamish General Hospital & $1(1)$ \\
\hline St Mary's Hospital & 0 \\
\hline Holy Family Hospital & 0 \\
\hline Powell River General Hospital & 0 \\
\hline Downtown Community Health Centre & 0 \\
\hline \multicolumn{2}{|l|}{ Practice disciplinet } \\
\hline Medicine & $31(33)$ \\
\hline Surgery & $17(18)$ \\
\hline Emergency & $12(13)$ \\
\hline Cardiology & $11(12)$ \\
\hline Psychiatry & $11(12)$ \\
\hline Family practice & $11(12)$ \\
\hline Residential care & 8 (9) \\
\hline Critical care & 7 (8) \\
\hline Nephrology & 7 (8) \\
\hline Community care & 7 (8) \\
\hline Palliative care & $6(6)$ \\
\hline Pediatrics & $6(6)$ \\
\hline HIV & $5 \quad(5)$ \\
\hline Neurosciences & $5 \quad(5)$ \\
\hline Bone marrow transplant & $4 \quad(4)$ \\
\hline Geriatrics & $3(3)$ \\
\hline Oncology & $2(2)$ \\
\hline Respirology & $2(2)$ \\
\hline Trauma & $2(2)$ \\
\hline Home IV program & $2(2)$ \\
\hline Infectious diseases & $1(1)$ \\
\hline Solid organ transplant & $1(1)$ \\
\hline
\end{tabular}

Characteristic

No. $(\%)$ of

Respondents $(n=93)$

\section{Experience (years)}

$\leq 10$

$55(59)$

$11-20$

$20(22$

$>20$

$18(19)$

\section{Highest level of training}

Bachelor of science in pharmacy 11 (12)

ACPR

$46(49)$

PharmD

$36(39)$

ACPR $=$ Accredited Canadian Pharmacy Residency.

*Practice sites were listed in the survey. Participants were allowed to identify more than one practice site.

tParticipants were allowed to identify more than one area of practice.

Research on diagnostic decision-making by physicians has established 2 core reasoning approaches: analytic (conscious or controlled) and non-analytic (unconscious or automatic). ${ }^{24,25}$ Some evidence has suggested that there are advantages to using both analytic and non-analytic approaches in clinical decisionmaking, ${ }^{19,24,26}$ although reliance on non-analytic methods is associated with greater diagnostic error. ${ }^{24,27-30}$ Also, clinical experience was not associated with improvements in diagnostic performance or patient outcomes when non-analytic approaches predominated. ${ }^{27}$ By contrast, analytic reasoning emphasizes the relationships between signs and symptoms and diagnosis according to the correct interpretation and incorporation of evidence from health care research. ${ }^{19}$ Richardson has categorized analytic methods into 6 traditions: descriptive, criteria-based, anatomic, pathophysiologic, probabilistic, and biopsychosocial. ${ }^{31}$ Depending on the area of practice, the extent to which clinicians rely on the various analytic traditions varies. ${ }^{25}$ Evidence-based practice puts the probabilistic tradition at the forefront, and this approach has been shown to improve diagnostic accuracy, reduce unnecessary testing, and minimize diagnostic error. ${ }^{25,32,33}$ The ability to quantify "the uncertainty in diagnosis and the discriminatory power of findings or tests" is the basis of probabilistic reasoning. ${ }^{25}$ However, research has shown that physicians lack sufficient understanding of the arithmetic components of diagnosis (e.g., sensitivity, specificity, likelihood ratios) and frequently avoid using diagnostic prob-

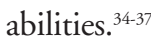

Published work exploring the performance of pharmacists as diagnosticians is extremely limited. In an editorial, Culbertson and others ${ }^{2}$ proposed application of the term "diagnosis" to pharmacy practice and defined pharmaceutical diagnosis as "the process used by pharmacists in identifying patient-specific, drug-related problems". They emphasized that acceptance of this concept would require changes in pharmacy education.

To the authors' knowledge, there is no published evidence exploring pharmacists' attitudes, behaviours, knowledge, and 
skills related to diagnosis. To this end, and because hospital pharmacists are already expected to make critical pharmacotherapeutic decisions on the basis of patient assessment and already have the authority to order laboratory tests, an assessment of the diagnostic attitudes, knowledge, and skills of a cohort of hospital pharmacists in several large multisite health regions was undertaken. The objectives of the study were to describe pharmacists' attitudes toward the role of diagnosis in pharmacotherapeutic problem-solving and to characterize the extent of their knowledge and skills related to the diagnosis of pharmacotherapeutically relevant problems.

\section{METHODS}

\section{Study Design and Participants}

This study was a prospective, observational survey-based cohort study.

The study cohort consisted of all clinical pharmacists within Lower Mainland Pharmacy Services (British Columbia) who spent at least $33 \%$ of their time in direct patient care roles. Potential participants were identified from departmental staff lists of clinical pharmacists.

\section{Survey Tool}

An online questionnaire was developed and deployed using www.SurveyMonkey.com. The survey (available by request to the authors) had 3 main sections: demographic characteristics, attitudes, and knowledge and skills.

The first section collected demographic information about participants, specifically site of practice, practice area, years in practice, and level of formal training.

The design of the other sections of the survey was based on the results of a literature search to identify previous relevant work involving pharmacists, methods used in other professions for evaluating diagnostic literacy and performance, and best methods for evaluating the accuracy of diagnostic tests.

The attitudes section of the survey sought to determine participants' level of agreement with a proposed definition of diagnosis, whether diagnostic knowledge and skill are important for pharmacists, and whether common drug-related issues are diagnostic in nature.

The knowledge and skills section of the survey consisted of 3 case scenarios designed to directly test participants' knowledge of the non-analytic and analytic diagnostic traditions and, among those preferring analytic traditions, which of the 6 analytic traditions were preferred. ${ }^{31}$ Knowledge of terminology related to the probabilistic diagnostic tradition (test sensitivity, test specificity, and likelihood ratios) and participants' ability to correctly apply diagnostic results were assessed. The case questions were "layered" to progressively present and elicit more advanced diagnostic reasoning. Including questions that tested participants' knowledge and skills allowed an assessment of where deficiencies lay (specifically, lack of knowledge of diagnostic parameters or inability to apply them or both). The iterative design of the questions was intended to reveal respondents' depth of knowledge. The final 3 questions of the knowledge and skills section tested participants' ability to apply likelihood ratios. Participants who stated a lack of familiarity with likelihood ratios were allowed to bypass these questions.

\section{Analytical Plan}

Simple descriptive statistics were used for the majority of the survey responses. Inferential statistics were used, where relevant, to evaluate emergent hypotheses such as relationships between respondents' experience and training and their responses to particular questions. Where relevant, qualitative responses were stratified according to level of agreement, then analyzed to identify themes. A cross-sectional analysis of the knowledge and skills section was performed to identify the questions with the least number of correct answers.

Required approval and permission to conduct the research was obtained from the Fraser Health Research Ethics Board and the Behavioural Research Ethics Board at the University of British Columbia. The research did not involve any sensitive information (e.g., health information or information that could affect employment status). Participants were not required to reveal their identity, nor did their responses make it possible for the investigators to determine individual identities.

\section{RESULTS}

A cohort of 266 clinical pharmacists was identified and contacted by e-mail. Of the pharmacists contacted, 94 (35\%) responded and provided consent electronically. Of the original cohort, $82(31 \%)$ fully completed the attitudes section of the survey, and 55 (21\%) completed the knowledge and skills section. The advanced knowledge and skills questions were completed by $16(6 \%)$ of potential respondents.

About one-quarter of the respondents (22/93 [24\%]) were from one large hospital, and one-third (31/93 [33\%]) were working in general medicine (Table 1).

Overall, $89 \%$ of respondents $(80 / 90)$ agreed with the proposed definition of "diagnosis", and 92\% (83/90) agreed that it is important for pharmacists to have skills related to the diagnosis of pharmacotherapeutically relevant conditions. A majority of respondents (79/90 [88\%]) agreed that it is important for them to have diagnostic skills in their own practice. Of the $10(11 \%)$ respondents who agreed somewhat or very little with the proposed definition of "diagnosis", 9 (90\%) agreed that pharmacists should possess the skills required for diagnosis of pharmacotherapeutically relevant conditions, and all agreed that diagnostic skills are required in 
their own practice. With respect to medication management as defined by the CSHP and ASHP, $81 \%$ of respondents (73/90) agreed that pharmacists require diagnostic skills to perform this task. Most respondents (82/90 [91\%]) reported ordering laboratory tests at least once weekly, and $80 \%$ of these $(66 / 82)$ agreed that they have the necessary skills to diagnose drugrelated issues in their patients.

The attitudes section of the survey revealed that $78 \%$ of the respondents who completed this section (64/82) felt they had the necessary skills to diagnose drug-related issues. Except for a weak positive correlation between years in practice and agreement with the statement "Diagnostic skills are important for pharmacists to have" (Spearman's rho $=0.24, p=0.033$ ), none of the results for attitudes correlated significantly with either years in practice or highest level of formal training.

The attitudes section of the survey also asked participants to assess 5 clinical scenarios that might require diagnostic skills, to indicate whether they considered the scenarios diagnostic in nature, and to indicate whether they agreed that a pharmacist should be involved in assessing them. These scenarios required interpreting a thyroid-stimulating hormone result, reading spirometry results, estimating cardiovascular risk, assessing syndrome of inappropriate antidiuretic hormone hypersecretion (SIADH), and assessing a potentially drug-related rash. Overall, a majority of the 82 respondents $(69$ [84\%]) agreed that they should be involved in assessing such issues, and the same number (69 [84\%]) agreed that the case problems were diagnostic in nature. Interpreting spirometry results to evaluate the indication for long-acting ß-agonist and calculating cardiovascular risk to evaluate indication for statin were associated with lower levels of agreement with these statements. For interpreting spirometry results, $49(60 \%)$ agreed and 23 (28\%) were undecided about whether pharmacists should be involved. For calculating cardiovascular risk, only 54 (66\%) of respondents agreed that the scenario was diagnostic in nature, but $71(87 \%)$ agreed that pharmacists should be involved in such assessments.

The section on diagnostic knowledge and skills revealed a general preference among participants for analytic rather than non-analytic approaches to diagnostic decision-making. Among the 6 analytic traditions, respondents' preferences varied depending on the nature of the scenario. The probabilistic tradition was not a preferred method for any of the cases. Respondents selected sensitivity and specificity as the most important characteristics of a diagnostic test for them to know, and likelihood ratio as the least important.

The knowledge and skills section presented 3 case scenarios to test pharmacists' knowledge of and ability to apply the 3 major probabilistic diagnostic metrics: test sensitivity, test specificity, and likelihood ratios. Respondents performed best on questions involving test sensitivity (average of 61\% of respondents with the correct answers) and worse on questions regarding test specificity (average of $48 \%$ with correct answers) and likelihood ratios (average of 39\% with correct answers) (Table 2). Many of the respondents who completed this section of the survey $(71 \%)$ professed a lack of familiarity with

Table 2. Participants' Performance on the Knowledge and Skills Section of the Survey

\begin{tabular}{|c|c|c|c|}
\hline $\begin{array}{l}\text { Aspect Tested and } \\
\text { Question No.* }\end{array}$ & $\begin{array}{l}\text { Total No. of } \\
\text { Respondents }\end{array}$ & $\begin{array}{c}\text { No. (\%) Who } \\
\text { Selected "I Don't Know" }\end{array}$ & $\begin{array}{l}\text { No. (\%) With } \\
\text { Correct Answert }\end{array}$ \\
\hline \multicolumn{4}{|l|}{ Using test sensitivity } \\
\hline Question 1.3 & 69 & $18 / 69(26)$ & $21 / 51(41)$ \\
\hline Question 2.4 & 60 & $5 / 60$ (8) & $34 / 55(62)$ \\
\hline Question 3.3 & 55 & $3 / 55 \quad$ (5) & $42 / 52(81)$ \\
\hline Mean \% & & $13 \%$ & $61 \%$ \\
\hline \multicolumn{4}{|l|}{ Using test specificity } \\
\hline Question 3.4 & 55 & $5 / 55 \quad(9)$ & 24/50 (48) \\
\hline Mean \% & & $9 \%$ & $48 \%$ \\
\hline \multicolumn{4}{|l|}{ Using likelihood ratios } \\
\hline Question 1.4 & 69 & 40/69 (58) & $24 / 29(83)$ \\
\hline Question 2.2 & 60 & $27 / 60(45)$ & $10 / 33(30)$ \\
\hline Question 2.3 & 60 & $33 / 60(55)$ & $10 / 27(37)$ \\
\hline Question 2.6 & 60 & $45 / 60(75)$ & $11 / 15(73)$ \\
\hline Question 3.5 & 55 & $39 / 55(71)$ & 2/16 (12) \\
\hline Question 3.6 & 16 & $3 / 16(19)$ & $0 / 13 \quad(0)$ \\
\hline Question 3.7 & 16 & $3 / 16(19)$ & $3 / 13(23)$ \\
\hline Question 3.8 & 16 & $8 / 16(50)$ & $4 / 8 \quad(50)$ \\
\hline Mean \% & & $49 \%$ & $39 \%$ \\
\hline \multicolumn{4}{|c|}{$\begin{array}{l}\text { *For each question number, the numeral preceding the decimal represents the case number }(1,2, \text { or } 3) \text {, and the } \\
\text { numeral following the decimal represents the question within that case. The number of questions differed for } \\
\text { each of the } 3 \text { cases. Also, each case had additional questions not related to the topics in this table (as indicated } \\
\text { by numbers missing from the sequence). }\end{array}$} \\
\hline
\end{tabular}


likelihood ratios, and an average of 49\% answered "I don't know" to the skills and knowledge questions involving likelihood ratios (Table 2).

Survey responses revealed the following common errors regarding sensitivity and specificity: considering the accuracy of a test to be the same as its sensitivity; confusing sensitivity with specificity; and lacking the knowledge that sensitivity and/or specificity do not provide information about the probability that a patient has or does not have the condition of interest. Respondents were even less familiar with likelihood ratios. In particular, there was a lack of knowledge about pretest and post-test probability cut-offs for likelihood ratios that result in clinically meaningful changes in post-test probability and a lack of knowledge about tools for estimating post-test probability (e.g., Fagan nomogram).

\section{DISCUSSION}

The areas of practice reported by survey respondents reflected the pharmacist population as recorded in the staff database of Lower Mainland Pharmacy Services, with the exception of the relative lack of pharmacists representing the following practice areas: infectious disease, home IV, and geriatrics. Hence, we infer that the attitudes expressed by the study participants likely reflected the attitudes of pharmacists in the target health authorities with a role in direct patient care.

Results for the attitudes component of the survey demonstrated that respondents agreed with the authors' definition of "diagnosis" and that, on the basis of this definition, they identified with their role as diagnosticians. It also appeared that a majority of respondents understood and accepted that diagnostic reasoning principles were relevant to their own practices and to pharmacy practice in general. Notably, there was a strong consensus among study participants that medication management, as highlighted by the future pharmacy initiatives (e.g., Canadian Blueprint for Pharmacy), will require that pharmacists possess diagnostic skills. Meanwhile, it appeared that pharmacists' responsibilities already included activities requiring diagnostic skills; for example, a majority of respondents reported ordering laboratory tests at least once a week.

Previous research has shown that using probabilistic diagnostic approaches has a beneficial effect on diagnostic accuracy and unnecessary laboratory testing. ${ }^{25,32,33}$ Applying probabilistic reasoning requires that pharmacists possess a cognitive skill set that Richardson ${ }^{31}$ summarized as follows: ability to interpret diagnostic uncertainty and express it using the language of probability, sufficient arithmetic skills, and ability to translate probabilities into diagnostic decisions and actions. Richardson ${ }^{31}$ also pointed out that, aside from having the necessary skills for using this approach correctly, clinicians must be able to recognize situations in which this approach does not apply. The results of the current survey indicated that respondents favoured the analytic diagnostic approach; however, they were also able to recognize situations where analytic diagnostic traditions other than the probabilistic tradition would be appropriate.

This study had some limitations. As expected, the dropout rate increased progressively as the assessment questions became more complex. In the attitudes section of the survey, some participants provided only partial responses. This problem was due to an error in the survey design, which allowed participants to move on to the next section before answering all of the questions in the attitudes section. However, we deemed the significance of this effect to be minimal. We also recognize that responses to an online survey, even one involving clinical scenarios, may not reflect the knowledge and skills that would be evident when functioning in an authentic clinical environment. The reported response rate $(35 \%)$ may underestimate the true response rate, because the master list $(n=266)$ included pharmacists who were either no longer with the organization or were not accurately identified as having a direct patient care role. Finally, the survey responses may reflect attitudes and skills that are not broadly representative of the profession, although it is impossible to predict in which direction this effect might have biased the findings.

The results of this survey point to several important areas for further research, including the need for more intensive observational research of pharmacists' actual diagnostic decision-making in practice, their preferences for different traditions according to the clinical scenario, and the best means of filling the requisite knowledge and skill gaps.

\section{CONCLUSIONS}

The pharmacists who responded to this survey strongly believed that diagnostic skills were important for them to solve drug-related problems, but they demonstrated low levels of knowledge and ability to apply concepts of probabilistic diagnostic reasoning. Opportunities to expand pharmacists' knowledge of diagnostic reasoning exist, and the findings reported here indicate that they would consider such professional development valuable. Further research is required to determine how best to accomplish this.

\section{References}

1. Blueprint for pharmacy - developed in partnership: the role of pharmacists. Ottawa (ON): Canadian Pharmacists Association; [updated 2008 Jun; cited 2010 Sep 12]. Available from: www.pharmacists.ca/ content/about_cpha/whats_happening/cpha_in_action/pdf/Blueprint Vision.pdf

2. Culbertson VL, Larson RA, Cady PS, Kale M, Force RW. A conceptual framework for defining pharmaceutical diagnosis. Am J Pharm Educ 1997;61(1):12-18.

3. Blueprint for pharmacy - developed in partnership. Ottawa $(\mathrm{ON})$ : Canadian Pharmacists Association; [updated 2008 Jun; cited 2010 Sep 12]. Available from: www.pharmacists.ca/content/about_cpha/whats_happening/ cpha_in_action/blueprint.cfm

4. Richardson E, Pollock AM. Community pharmacy: moving from dispensing to diagnosis and treatment. BMJ 2010;340:c2298. 
5. Medication management (adapting a prescription). Vancouver (BC): College of Pharmacists of British Columbia; [no date; cited 2010 Sep 12]. Available from: www.bcpharmacists.org/about_us/key_initiatives/index/ articles29.php

6. Pharmacists and Pharmacy Technicians Profession Regulation, Alta Reg. 129/2006. Edmonton (AB): Alberta Queen's Printer; 2006 [cited 2010 Sep 12]. Available from: www.qp.alberta.ca/574.cfm?page $=2006$ 129.cfm \&leg_type=Regs\&isbncln=9780779727186 ("Restricted activities" section, "Clinical pharmacists" subsection).

7. Continued care prescriptions agreement between the Nova Scotia College of Pharmacists and the College of Physicians and Surgeons of Nova Scotia. Halifax (NS): Nova Scotia College of Pharmacists; [no date; cited 2010 Sep 12]. Available from: http://nspharmacists.ca/legislation/documents/ ContinuedCarePrescriptionsAgreement.pdf

8. Regulations of the New Brunswick Pharmaceutical Society: prescribing by pharmacists. Moncton (NB): New Brunswick Pharmaceutical Society; 2010 Jun 11 [cited 2010 Sep 12]. Available from: www. nbpharmacists.ca/LinkClick.aspx?fileticket=ezNCFfcjrSg\%3d\&tabid=244 \&mid=686 (access to content restricted).

9. Chi J. Power of pen: pharmacist prescribing is advancing slowly but surely throughout the country. Drug Top 2000;144(20):40.

10. Summary: pharmacist prescribing authority status across Canada. Ottawa (ON): Canadian Pharmacists Association; [updated 2009 Oct; cited 2010 Sep 12]. Available from: www.pharmacists.ca/content/about_cpha/ who_we_are/policy_position/pdf/PharmacistsPrescribingInCanada.pdf

11. 2015 initiative. Bethesda (MD): American Society of Health-System Pharmacists; [no date; cited 2010 Sep 12]. Available from: www.ashp. org $/ 2015$

12. CSHP 2015 - targeting excellence in pharmacy practice. Ottawa (ON): Canadian Society of Hospital Pharmacists; [no date; cited 2010 Sep 12]. Available from: www.cshp.ca/programs/cshp2015

13. Section 4.7: Pharmacist authorities. In: Formulary: policies and procedures. Vancouver (BC): Vancouver Coastal Health, Clinical Services Unit, Pharmaceutical Sciences, Vancouver Acute; [no date; cited 2010 Sep 12]. Available from: www.vhpharmsci.com/VHFormulary/Policies/4.7PHARMACIST-AUTHORITY.htm

14. Update on ordering of lab tests by pharmacists. ACP News [serial on Internet] 2009 Fall [cited 2010 Sep 12];:3. Available from: https:// pharmacists.ab.ca/document_library/ACPCurrentNewsletter.pdf (published by Alberta College of Pharmacists)

15. Jacobs MR. Conference report: reimbursement for pharmaceutical care: the pharmacist's diagnosis. Medscape Pharm [serial on Internet] 2000 [cited 2010 Sep 12];1(1). Available from: www.medscape.com/viewarticle/ 408561 5 (membership required to access content)

16. Hall J. Leaving prescribing to us: MDs. The Star.com 2008 Nov 21 [cited 2010 Sep 12]. Available from: www.thestar.com/HealthZone/News Features/article/540922

17. Pharmacy allergy testing and diagnosis - the BSACI view. London (UK): British Society for Allergy and Clinical Immunology; [no date; cited 2010 Sep 12]. Available from: www.bsaci.org/index.php?option=com content\&task=view\&id=148\&Itemid=111

18. Ontario pharmacists could soon prescribe drugs. Toronto $(\mathrm{ON})$ : The Canadian Press; [updated 2008 Jun 2; cited 2010 Sep 10]. Available from: www.cbc.ca/health/story/2008/06/02/pharmacists-ontario.html

19. Rutter P. Community pharmacy: symptoms, diagnosis and treatment. Churchill Livingstone; 2004

20. "Diagnosis". In: Mellonis illustrated medical dictionary. 4th ed. London (UK): The Parthenon Publishing Group; 2002. p. 167.

21. "Diagnosis". In: WCPT position statements. Education. Appendix C: Glossary. London (UK): World Confederation of Physical Therapy; [updated 2010 Apr 30; cited $2010 \mathrm{Jul} \mathrm{13].} \mathrm{Available} \mathrm{from:} \mathrm{www.wcpt.org/}$ node/29562

22. "Diagnosis". In: Oxford English Dictionary [Internet version]. 2nd ed. New York (NY): Oxford University Press; 1989 [cited 2010 Jul 13]. Available from: http://oed.com

23. "Diagnosis". In: International dictionary of medicine and biology. Vol 1. New York (NY): Wiley \& Sons; 1986. p. 780.
24. Eva KW. What every teacher needs to know about clinical reasoning. Med Educ 2005;39(1):98-106.

25. Pelaccia T, Tardif J, Triby E, Charlin B. An analysis of clinical reasoning through a recent and comprehensive approach: the dual-process theory. Med Educ Online 2011;16:5890.

26. Eva KW, Hatala RM, Leblanc VR, Brooks LR. Teaching from the clinical reasoning literature: combined reasoning strategies help novice diagnosticians overcome misleading information. Med Educ 2007; 41(12):1152-1158

27. Eva KW. The aging physician: changes in cognitive processing and their impact on medical practice. Acad Med 2002;77(10 Suppl):S1-S6.

28. Brooks LR, LeBlanc VR, Norman GR. On the difficulty of noticing obvious features in patient appearance. Psychol Sci 2000;11(2):112-117.

29. Eva KW, Brooks LR. The under-weighting of implicitly generated diagnoses. Acad Med 2000;75(10 Suppl):S81-S83.

30. Eva KW. The influence of differentially processing information on diagnostic decision making [dissertation]. Hamilton (ON): McMaster University; 2001

31. Richardson WS. We should overcome the barriers to evidence-based clinical diagnosis! J Clin Epidemiol 2007;60(3):217-227.

32. Richardson WS. Evidence-based diagnosis: more is needed [EBM note]. Evid-Based Med 1997;2:70-71.

33. Knottnerus JA, editor. The evidence base of clinical diagnosis. London (UK): BMJ Books; 2002.

34. Sox CM, Doctor JN, Koepsell TD, Christakis DA. The influence of types of decision support on physicians' decision making. Arch Dis Child 2009;94(3):185-190.

35. Casscells W, Schoenberger A, Graboys TB. Interpretation by physicians of clinical laboratory results. N Engl J Med 1978;299(18):999-1001.

36. Bergus G, Vogelgesang S, Tansey J, Franklin E, Feld R. Appraising and applying evidence about a diagnostic test during a performance-based assessment. BMC Med Educ 2004;4:20.

37. Reid MC, Lane DA, Feinstein AR. Academic calculations versus clinical judgments: practicing physicians' use of quantitative measures of test accuracy. Am J Med 1998;104(4):374-380.

Kseniya Chernushkin, BSC(Pharm), ACPR, is a Clinical Pharmacist Vancouver General Hospital, Vancouver, British Columbia.

Peter Loewen, BSC(Pharm), ACPR, PharmD, FCSHP, is the Director of the Doctor of Pharmacy Programs and an Assistant Professor, Faculty of Pharmaceutical Sciences, The University of British Columbia, Vancouver, British Columbia.

Jane de Lemos, BPharm, PharmD, MSc(Epid), is a Clinical Pharmacy Specialist, Emergency Medicine, Richmond Hospital, Richmond, British Columbia.

Amneet Aulakh, BSc(Pharm), ACPR, PharmD, is a Clinical Pharmacy Specialist (Medicine), Vancouver General Hospital, Vancouver, British Columbia.

Joanne Jung, BSC(Pharm), ACPR, is a Clinical Pharmacy Specialist (Nephrology), St Paul's Hospital, Vancouver, British Columbia.

Karen Dahri, BSc, BSc(Pharm), ACPR, PharmD, is a Clinical Pharmacy Specialist (Medicine), Vancouver General Hospital, Vancouver, British Columbia.

\section{Address correspondence to:}

Kseniya Chernushkin

Vancouver General Hospital

855 West 12th Avenue

Vancouver BC V5Z $1 \mathrm{M} 9$

e-mail: kseniya.chernushkin@vch.ca 